\title{
Fabrication of ultra thin and aligned carbon nanofibres from electrospun polyacrylonitrile nanofibres
}

\author{
JAVED RAFIQUE ${ }^{a, b, *}$, JIE YU ${ }^{a, *}$, XIAOXIONG ZHA $^{\mathrm{c}}$ and KHALID RAFIQUE ${ }^{\mathrm{b}}$ \\ ${ }^{a}$ Department of Materials Science and Engineering, Shenzhen Graduate School, \\ Harbin Institute of Technology, Shenzhen 518055, China \\ ${ }^{\mathrm{b}}$ Pakistan Atomic Energy Commission (PAEC), P.O. Box 1114, Islamabad, Pakistan \\ ${ }^{\mathrm{c}}$ Structural and Geotechnical Engineering Research Centre (SGERC), Shenzhen Graduate School, Harbin Institute of \\ Technology, Shenzhen 518055, China
}

MS received 16 May 2009; revised 5 June 2009

\begin{abstract}
Ultra thin and aligned carbon nanofibres (CNFs) have been fabricated by heat treatment from aligned polyacrylonitrile (PAN) nanofibre precursors prepared by electrospinning. The alignment of the precursor nanofibres was achieved by using a modified electrospinning set up developed recently, where a tip collector was used to collect and align the nanofibres. The average diameter of the aligned CNFs is about $80 \mathrm{~nm}$. The stabilization and carbonization behaviour were studied mainly based on the randomly oriented PAN nanofibres. The effects of stabilization and carbonization temperatures, temperature-increasing rates, and with and without substrates on the morphology and structure of the CNFs were investigated. Fourier transform infrared spectroscopy, scanning electron microscopy, X-ray diffraction, transmission electron microscopy and Raman spectroscopy were used to characterize the structure of the CNFs and thermogravimetric/ differential temperature analysis was used to evaluate the thermal behaviour of PAN nanofibres.
\end{abstract}

Keywords. Nanofibres; carbon; nanotechnology; oxidation; aligned.

\section{Introduction}

Carbon is a material of great importance in industrial application owing to its diversity in structure and property. Among various carbon nanostructures, carbon nanofibres (CNFs) have recently attracted researchers from diverse areas due to their wide application potential, such as candidate materials for hydrogen storage ( $\mathrm{Zhu}$ et al 2003), electronic components (Cui et al 2004), catalysts and catalytic supports (Endo et al 2004), bio-analytical tools (Yokoyama et al 2005), functional composites (Hammel et al 2004), field emission devices (Li et al 2005), and substitutes for carbon nanotubes (CNTs) (Singh et al 2002). It is known that the fibre mechanical properties improve substantially with a decrease in the fibre diameter. For example, the tensile strength of the CNF webs increased by two times when the average diameter decreased from 800 to $300 \mathrm{~nm}$ (Kim et al 2007). Although the fibres prepared by traditional spinning methods are generally 5-500 $\mu \mathrm{m}$ in diameter (Yang et al 2003), a novel fibre production technique known as electrospinning offers the possibility of preparing ultra-thin fibres below $1 \mu \mathrm{m}$ readily (Reneker and Chun 1996; Reneker et al 2000; Deitzel et al 2001; Huang et al 2003).

*Author for correspondence (msejyu@yahoo.com)
In recent years, electrospinning has received great interest due to its simplicity and versatility for fabricating ultrathin and continuous nanofibres. In electrospinning a polymer solution or melt is kept in a reservoir with a capillary for fluid spinning and high voltage is applied between the fluid and ground collector. Under the action of applied electrical field the charged drop of the polymer solution at the tip of the capillary becomes conical, termed as Taylor cone (Reneker et al 2000). At a critical field when the electrostatic force overcomes the surface tension force holding the droplet, a charged solution jet is ejected from the Taylor cone. The charged jet then undergoes a complex process of whipping, stretching, and solidification as moving towards the grounded collector, which results in the formation of solid fibres as small as tens of nanometers in diameter. By using appropriate organic electrospun fibres as precursors, various inorganic nanofibres such as CNFs can be prepared by subsequent calcinations. However, reports on the preparation of CNFs from the electrospun precursor fibres are lacking. The diameters of CNFs so far prepared are generally several micrometers to more than $100 \mathrm{~nm}$ (Chun et al 1999; Kim and Yang 2003; Li et al 2003; Yang et al 2003; Kim 2004; Kim et al 2004a, 2007; Chung et al 2005; Rutledge et al 2006; Sutasinpromprae et al 2006). In addition, although the aligned CNFs were prepared by rotating the collector (Kim et al 2004b; Rutledge et al 
2006) and double-electrode collector (Li et al 2003), it is necessary to develop simple and new technique for producing the aligned CNFs on large scale at low cost.

In this paper, the aligned CNFs with the average diameter of $80 \mathrm{~nm}$ were fabricated from the electrospun polyacrylonitrile (PAN) nanofibres by stabilization and carbonization. The alignment of the precursor polymer nanofibres was achieved by using a newly developed technique. This study helps to reveal the stabilization and carbonization behaviour of the CNFs and provides a simple and effective method for preparing ultra-thin aligned CNFs.

\section{Experimental}

PAN (Aldrich, $M_{\mathrm{w}}=86200$ ) and $N, N$-dimethylformamide (DMF) solution was prepared in the range from 9-12.5\% (w/v) by magnetic stirring for about $12 \mathrm{~h}$.

The aligned precursor nanofibres were electrospun from PAN solution by using a newly developed electrospinning set up (Rafique et al 2007). Figure 1 shows a schematic of the modified electrospinning set up.

This set up consists of a syringe with needle, a collector, and a support plate. Different from the conventional electrospinning set up, the grounded collector electrode here is a metal wire of only $2 \mathrm{~mm}$ in diameter, fixed in a hole centred at an electrode holder such as a wooden board. Because of the small size of the grounded electrode this collector has been termed 'tip collector'. In this set up, the opening of the hypodermic needle was towards the collector, as shown in figure 1. Positive terminal of the power supply was dipped into the solution and the counter electrode was placed in the electrode holder during this work. In response to the applied electrospinning voltage, the droplet formed at the needle tip was deformed into the conical shape called 'Taylor cone' and a further increase in the applied voltage ejected a jet from the apex of the Taylor cone which travelled towards the counter electrode. As the electrospun fibre travelled towards the

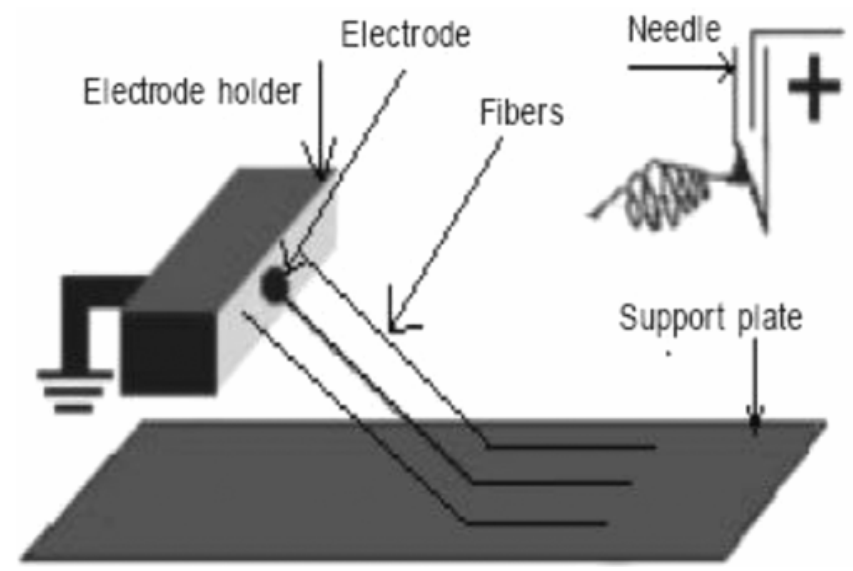

Figure 1. Schematic of modified electrospinning set up for the production of aligned polymer nanofibres. counter electrode, due to higher consumption of solution than the supply at the needle tip, the fibre jet broke and a single fibre was produced in this way. Just after the rear end of a single fibre left the needle tip a new solution drop started to accumulate at the tip again and the next single fibre formed by a similar process. In this way the fibres are produced one by one. At the moment, the front end of the fibre reached the collector and it adhered to the collector surface and was fixed. Subsequently, the rear part of the fibre fell towards the support plate and lied on its surface. During the above processes, the whipping spiral relaxed gradually due to the repelling force between the adjacent circular segments of the charged fibres and a straight nanofibre was finally obtained spanning the gap between the collector and the support palate. Once a single fibre was formed as described above, the next fibre was repelled by the formerly deposited fibre when it approached the collector and landed towards the support plate, as a result of which the next fibre arranged itself in parallel to the former one. The detailed results on the set up and production mechanism of the aligned nanofibres have been published elsewhere (Rafique et al 2007).

Conversion of the PAN nanofibres into the CNFs was accomplished in two steps, viz. stabilization and carbonization. Stabilization was carried out in the temperature range from $200-350^{\circ} \mathrm{C}$ at different heating rates from $0 \cdot 5-5^{\circ} \mathrm{C} / \mathrm{min}$ in air for $1 \mathrm{~h}$. Carbonization was carried out in the temperature range from $750-1100^{\circ} \mathrm{C}$ at different heating rates from $0.5-5^{\circ} \mathrm{C} / \mathrm{min}$ under nitrogen for $1 \mathrm{~h}$. The PAN nanofibres were also electrospun and subsequently carbonized on quartz substrate in order to observe the effects of applying tensile stress during stabilization and carbonization.

\section{Characterization}

In order to determine the stabilization temperature of the electrospun PAN nanofibres thermogravimetric/differential temperature analysis (TG/DTA, WCT-2C) was performed at a heating rate of $5^{\circ} \mathrm{C} / \mathrm{min}$ in air. Fourier transform infrared spectroscopy (FTIR, NICOLET-380) was used to characterize the chemical bonding of the as spun and heat treated nanofibres. The morphology of the fibres was characterized by scanning electron microscope (SEM, Hitachi S-4700). All the nanofibre samples were gold coated for $90 \mathrm{~s}$ before SEM measurements. Raman spectroscopy (RM-1000 Micro Raman Spectrometer) and X-ray diffraction (XRD, XD-2) were used to characterize the structure of the CNFs. High-resolution transmission electron microscopy (HRTEM, JEOL-2010F) was used to investigate the crystallinity of the CNFs.

\section{Results and discussion}

Initially, randomly distributed PAN nanofibrous mats were prepared by using the conventional electrospinning 
system, where the plate collector was placed vertically below the syringe needle. Figure 2 shows typical SEM image of random nanofibre mat and the diameter of the nanofibres range from $180-220 \mathrm{~nm}$. The fibres are straight and average diameter is about $200 \mathrm{~nm}$. In our study it was found that diameters of the electrospun nanofibres depend to a great extent on the concentration of the solution, needle diameter and the electric field strength. Higher solution concentrations result in thicker fibres and lower concentration produces thinner fibres. Bigger diameter needle supplies more solution to the tip as compared to smaller diameter needle and hence the result in thicker fibres. Generally, the fibre diameter decreases with increasing electric field strength. By choosing the solution concentration of $10 \%(\mathrm{w} / \mathrm{v})$ and electric field strength of $2 \mathrm{kV} / \mathrm{cm}$ the diameter of the PAN nanofibres was controlled around $200 \mathrm{~nm}$ as shown in figure 2 .

Conversion of polymer nanofibres into CNFs was performed through stabilization and carbonization. To determine the stabilization temperature, TG/DTA was performed in air from room temperature to $600^{\circ} \mathrm{C}$ and is shown in figure 3(a). The sharp exothermic peak at about $290^{\circ} \mathrm{C}$ indicates the cyclization of the nitrile group in PAN and corresponds to the oxidative stabilization process. The weight loss around $280-290^{\circ} \mathrm{C}$ is due to the evaporation of volatiles and then from $300-600^{\circ} \mathrm{C}$ due to combustion.

Figure 3(b) shows FTIR spectra of the nanofibres thermally cured at 200,350 and $750^{\circ} \mathrm{C}$ in comparison with that of as spun polymer nanofibres. The FTIR spectrum of the sample treated at $200^{\circ} \mathrm{C}$ showed a notable reduction in peak intensities at 1452, 1733, 2241, and $2920 \mathrm{~cm}^{-1}$ indicating abrogation of aliphatic $\mathrm{C}-\mathrm{H}$ bands (1452, $\left.2920 \mathrm{~cm}^{-1}\right), \mathrm{C}=\mathrm{O}$ bond for methyl acrylate $\left(1733 \mathrm{~cm}^{-1}\right)$ and saturated nitriles at $2241 \mathrm{~cm}^{-1}$ in com-

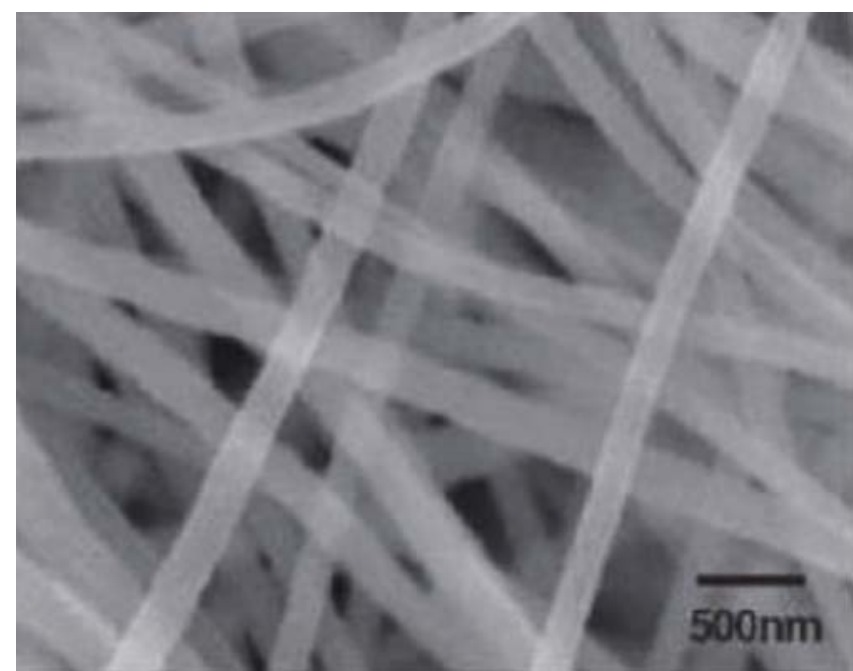

Figure 2. A typical SEM image of the random PAN nanofibres. parison to the as spun polymer nanofibres. FTIR spectrum of the sample thermally cured at $350^{\circ} \mathrm{C}$ showed some features related to the structural changes. The band at $804 \mathrm{~cm}^{-1}$ is probably due to $\mathrm{C}=\mathrm{C}=\mathrm{H}$ bonding and that at $1590 \mathrm{~cm}^{-1}$ band is due to $\mathrm{C}=\mathrm{N}, \mathrm{C}=\mathrm{C}, \mathrm{N}=\mathrm{H}$ mixed bonds. Another band at $1370 \mathrm{~cm}^{-1}$ might be due to the nascent amorphous structure (inception of D-peak). Based on the above investigations, $300^{\circ} \mathrm{C}$ was chosen as the stabilization temperature for the preparation of CNFs in this study.

Figure 4 shows SEM images of the CNFs prepared at different conditions. The heating rates are $1^{\circ} \mathrm{C} / \mathrm{min}$ for all the three samples. Figure 4(a) shows SEM image of the $\mathrm{CNF}$ mat carbonized at $750^{\circ} \mathrm{C}$ for $1 \mathrm{~h}$. Before carbonization the nanofibres were stabilized for $1 \mathrm{~h}$ at $300^{\circ} \mathrm{C}$ with a heating rate of $1^{\circ} \mathrm{C} / \mathrm{min}$. The average diameter of the nanofibres was found to be around $100 \mathrm{~nm}$.

Figure 4(b) shows SEM images of the CNF mat carbonized at $1100^{\circ} \mathrm{C}$. The average diameter of the nanofibres at this temperature was about $80 \mathrm{~nm}$. The decrease in diameter for the $\mathrm{CNFs}$ carbonized at $1100^{\circ} \mathrm{C}$ compared
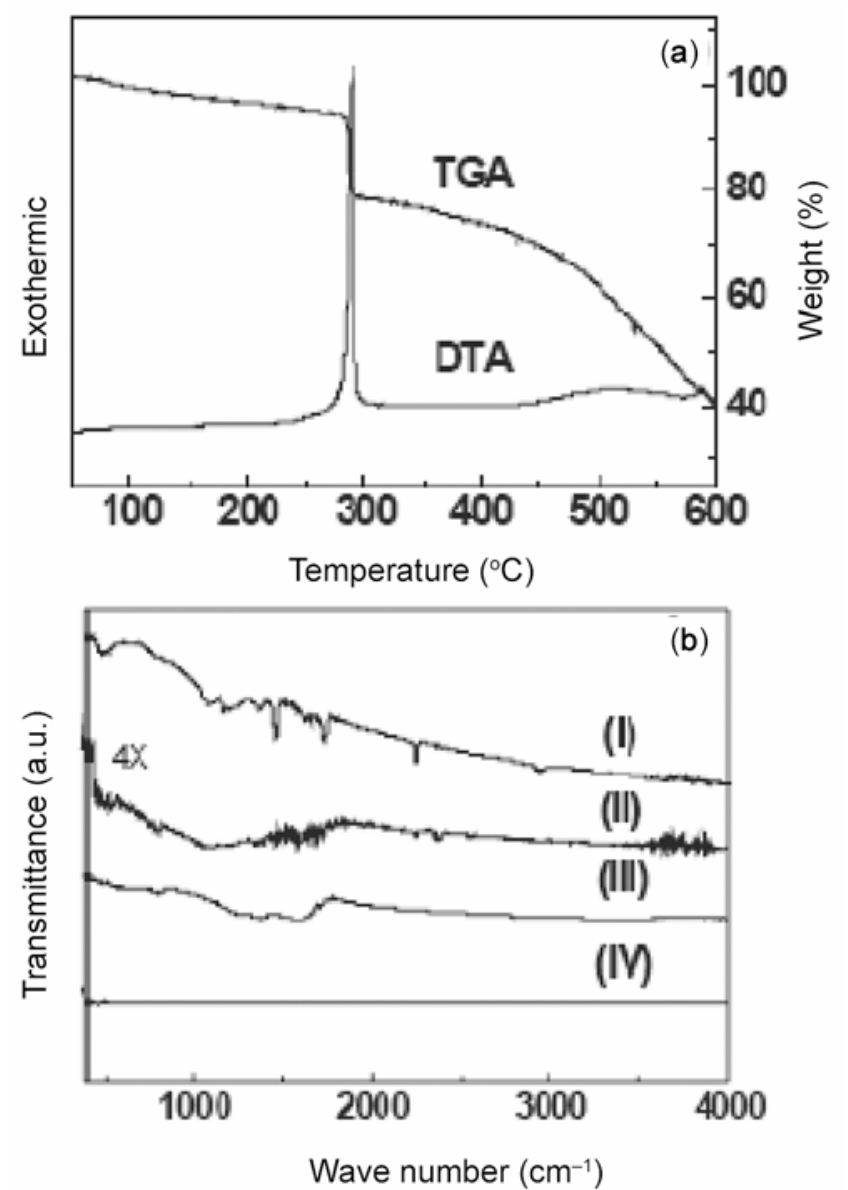

Figure 3. (a) DT/TGA traces of PAN nanofibres in air and (b) FTIR spectra of different samples: (I) PAN nanofibres; (II) PAN nanofibres stabilized at $200^{\circ} \mathrm{C}$; (III) PAN nanofibres stabilized at $350^{\circ} \mathrm{C}$; and (IV) CNFs. 
with that at $750^{\circ} \mathrm{C}$ may be caused by higher density changes at higher temperature. This reduction in diameter from polymer nanofibres to the CNFs is in agreement with the previous reports (Zussman et al 2005). Figure 4(c) shows the SEM image of the CNFs that were electrospun directly on the quartz substrate. It is indicated
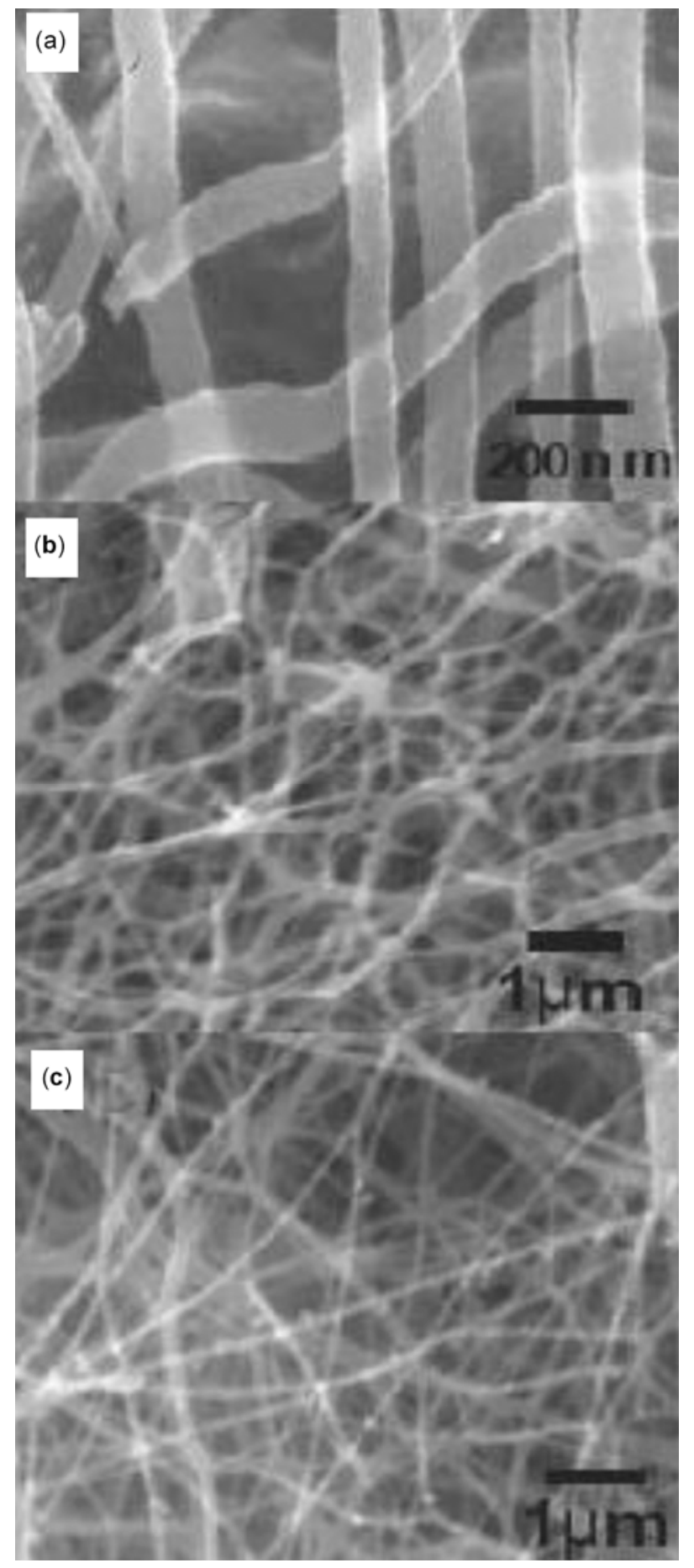

Figure 4. SEM images of the CNFs prepared at different conditions: (a) carbonized at $750^{\circ} \mathrm{C},(\mathbf{b})$ carbonized at $1100^{\circ} \mathrm{C}$, (c) carbonized at $1100^{\circ} \mathrm{C}$ for the sample deposited on the substrate. that the nanofibres carbonized on substrates are much straighter and thinner than that of the free mats. The fibres will inevitably be densified and shrink during stabilization and carbonization. The nanofibres were fixed on the substrate from many points and these remained fixed during stabilization and carbonization process, so during stabilization and carbonization the fixation of the nanofibres has an effect similar to that of applied stretching on the nanofibres. In this case the densification due to the loss of non-carbon species was mainly accommodated by the shrinkage along the radial direction during heat treatment. Consequently, due to the fixation of the nanofibres onto the substrate from many points the CNFs on the substrates (these nanofibres cannot move) are straighter due to applied stretch and thinner than that of the free samples due to higher densification along the radial direction. As shown in figures 4(b) and (c), the diameter of CNFs decreased to $60 \mathrm{~nm}$ for the sample on the substrate from $80 \mathrm{~nm}$ for the free sample.
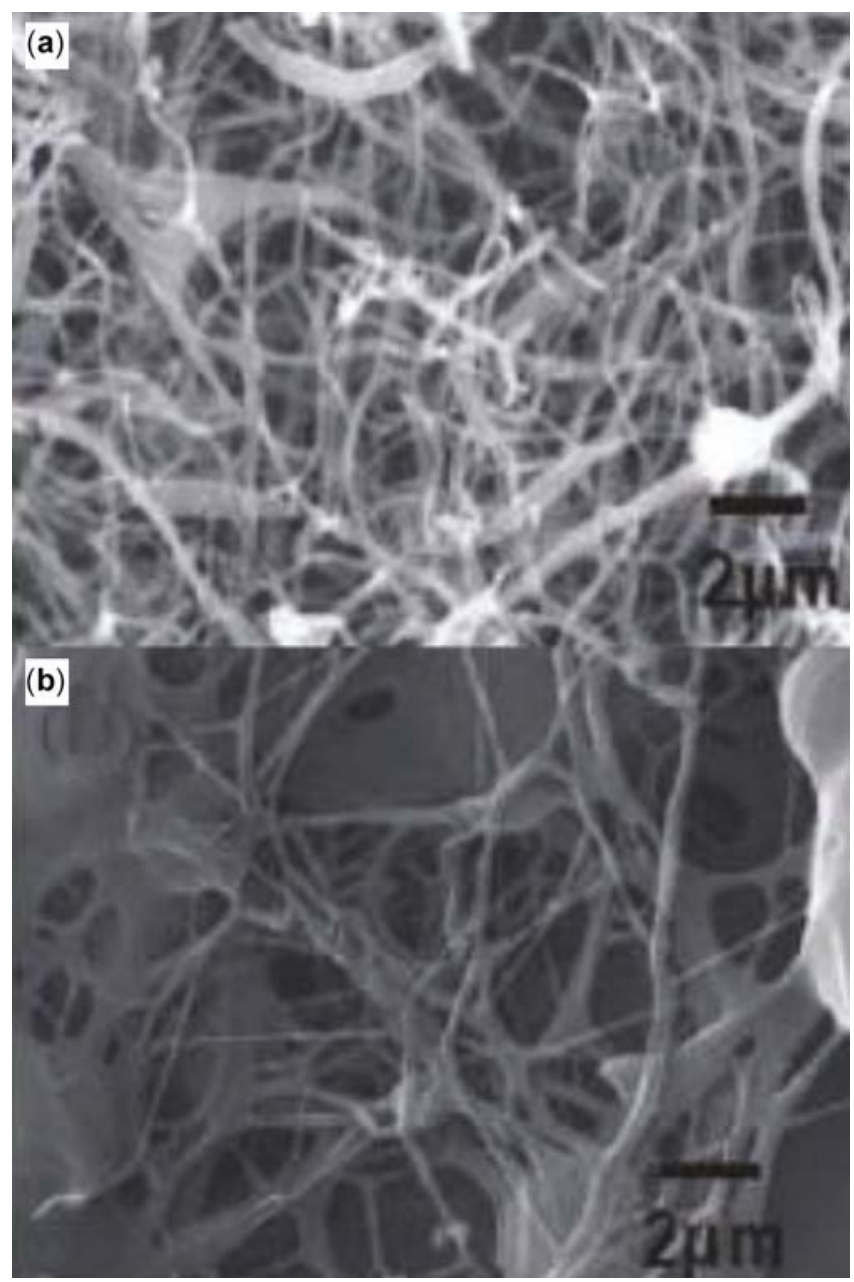

Figure 5. SEM images of the CNFs prepared at different conditions. (a) Stabilized at $300^{\circ} \mathrm{C}$ with a heating rate of $1^{\circ} \mathrm{C} / \mathrm{min}$ and carbonization at $1100^{\circ} \mathrm{C}$ with a heating rate of $5^{\circ} \mathrm{C} / \mathrm{min}$ and (b) stabilized at $200^{\circ} \mathrm{C}$ with a heating rate of $1^{\circ} \mathrm{C} / \mathrm{min}$ and carbonization at $1100^{\circ} \mathrm{C}$ with a heating rate of $5^{\circ} \mathrm{C} / \mathrm{min}$. 
The processes of stabilization and carbonization were further investigated by varying the stabilization and carbonization conditions. Figure 5(a) shows the SEM image of the CNFs stabilized at $300^{\circ} \mathrm{C}$ and carbonized at $1100^{\circ} \mathrm{C}$ with a heating rate of $5^{\circ} \mathrm{C} / \mathrm{min}$. It is clearly observed that the nanofibres tend to break during carbonization at higher heating rate. The production rate of the volatile by-products increases with increasing temperature-increasing rate during carbonization.

The nanofibres may be damaged or broken by the rapid swelling of the volatile by-products if their production rate is too high at high heating rate. Meanwhile, the rapid release of the by-products also generates stress inside the fibres that causes the fibres to break sometimes. Figure 5(b) shows SEM image of the nanofibres stabilized at $200^{\circ} \mathrm{C}$ and carbonized at $1100^{\circ} \mathrm{C}$ at a heating rate of $5^{\circ} \mathrm{C} / \mathrm{min}$. It is evidently observed that the nanofibres lost their integrity and merged together. This is because the nanofibres were not properly stabilized at $200^{\circ} \mathrm{C}$ and melt during heating for carbonization, and thus result in the emergence of the nanofibres. XRD was utilized to verify the carbonization of the nanofibres. Figure 6 shows XRD pattern of the CNFs carbonized at $1100^{\circ} \mathrm{C}$ and the PAN nanofibres. A broad XRD peak at about $2 \theta=17^{\circ}$ for PAN nanofibres indicates low crystallinity, suggesting that PAN molecules in the fibres did not have enough time to crystallize before solidification during electrospinning.

Two distinct XRD peaks at about $25^{\circ}$ and $44^{\circ}$ for the CNFs carbonized at $1100^{\circ} \mathrm{C}$ indicates (002) and (10) layers of graphite structure (Babu and Seehra 1996). It is attested that the PAN nanofibres were well carbonized and graphitized.

Figure 7 shows the Raman spectra of PAN-based CNFs derived at different temperatures. Two peaks around 1360

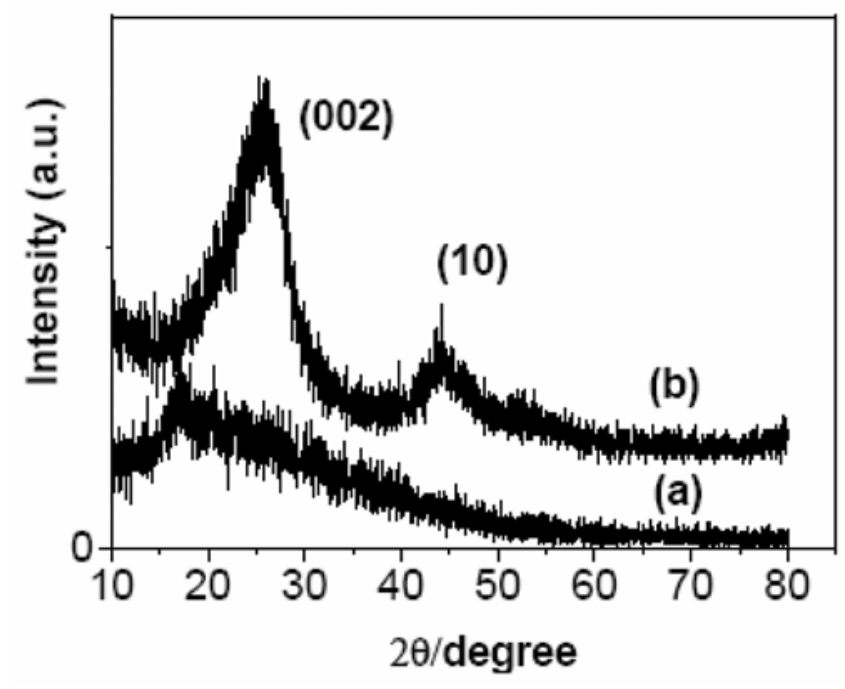

Figure 6. XRD patterns of (a) electrospun PAN nanofibres and (b) $\mathrm{CNF}$ s carbonized at $1100^{\circ} \mathrm{C}$. and $1580 \mathrm{~cm}^{-1}$ were clearly observed for all the samples cabonized at temperatures from $750-1100^{\circ} \mathrm{C}$, which are typical characteristics of the graphitic carbon. The peak around $1580 \mathrm{~cm}^{-1}$ can be identified as the $G$ peak of crystalline graphite arising from zone-centre $E_{2 \mathrm{~g}}$ mode, and the peak around $1360 \mathrm{~cm}^{-1}$ as the $D$ peak assigned to an $A_{1 \mathrm{~g}}$ zone-edge phonon induced by the disorder associated with finite crystalline size.

From Raman spectra it is observed that $R$-value, the intensity ratio of the $D$ and $G$ peaks, decreases with increasing carbonization temperature, indicating that the degree of graphitization increases correspondingly. Knight and White (1989) developed an empirical formula for the relationship between $R$ and the crystallite domain size $L_{\mathrm{a}}$ of graphite as $L_{\mathrm{a}}=4 \cdot 4 / R \mathrm{~nm}$. Using this equation, $L_{\mathrm{a}}$ was estimated to be in the range from $4 \cdot 17-4 \cdot 62 \mathrm{~nm}$ with increasing carbonization temperature from 750 $1100^{\circ} \mathrm{C}$ as shown in figure $7(\mathrm{~b})$.

Finally, the aligned PAN nanofibres were prepared by using the set up shown in figure 1. Figure 8(a) shows the
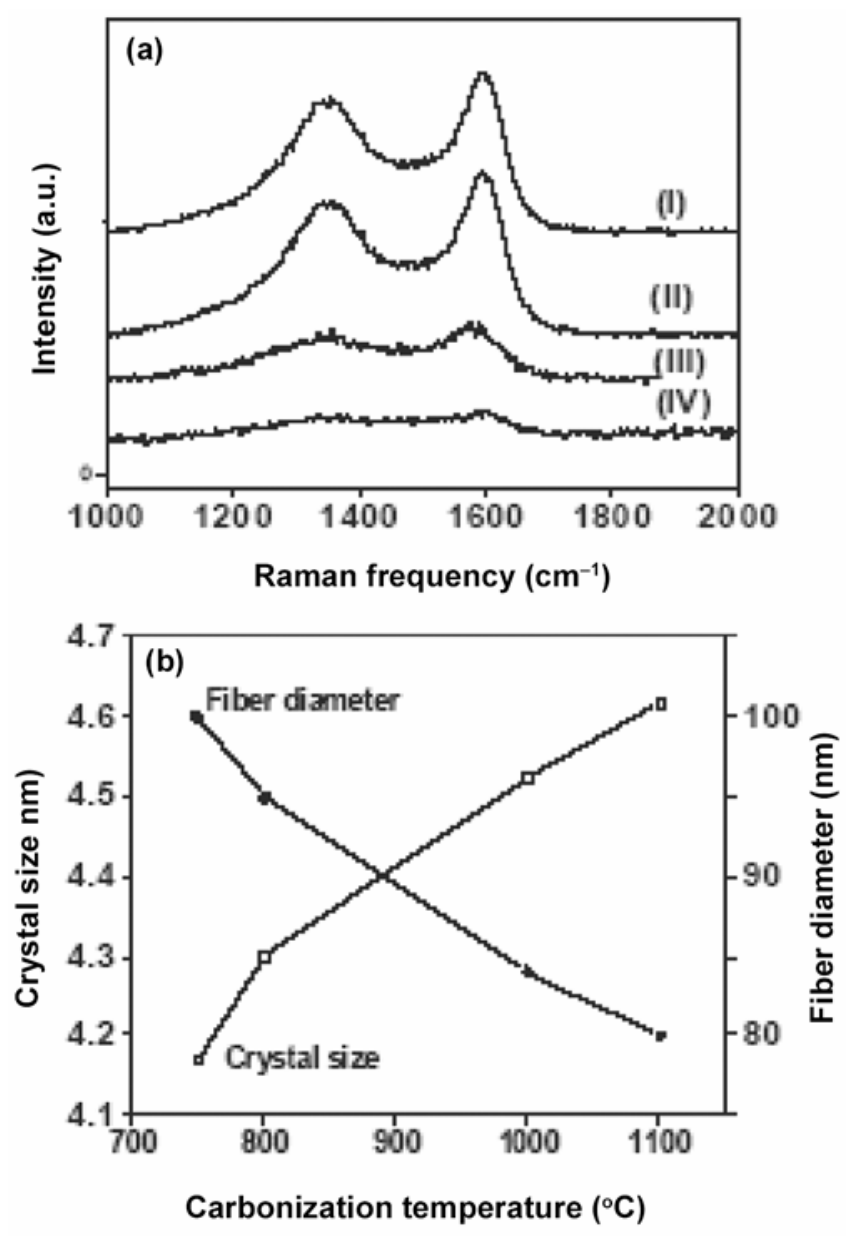

Figure 7. (a) Raman spectra of the $\mathrm{CNFs}$ carbonized at different temperatures: (I) $1100^{\circ} \mathrm{C}$; (II) $1000^{\circ} \mathrm{C}$; (III) $800^{\circ} \mathrm{C}$; (IV) $750^{\circ} \mathrm{C}$ and (b) crystal size and fibre diameter vs carbonization temperature. 
SEM image of aligned PAN nanofibres electrospun from a concentration of $11 \%(\mathrm{w} / \mathrm{v})$ with diameter in the range from $120-170 \mathrm{~nm}$ and the average diameter is about $140 \mathrm{~nm}$. Such a thin diameter of PAN nanofibres was achieved by using new electrospinning set up and adjusting the electrospinning parameters properly. Here the advantage of this set up lies in that the nanofibres were further thinned during suspension across the gap between tip collector and support plate (figure 1). These aligned
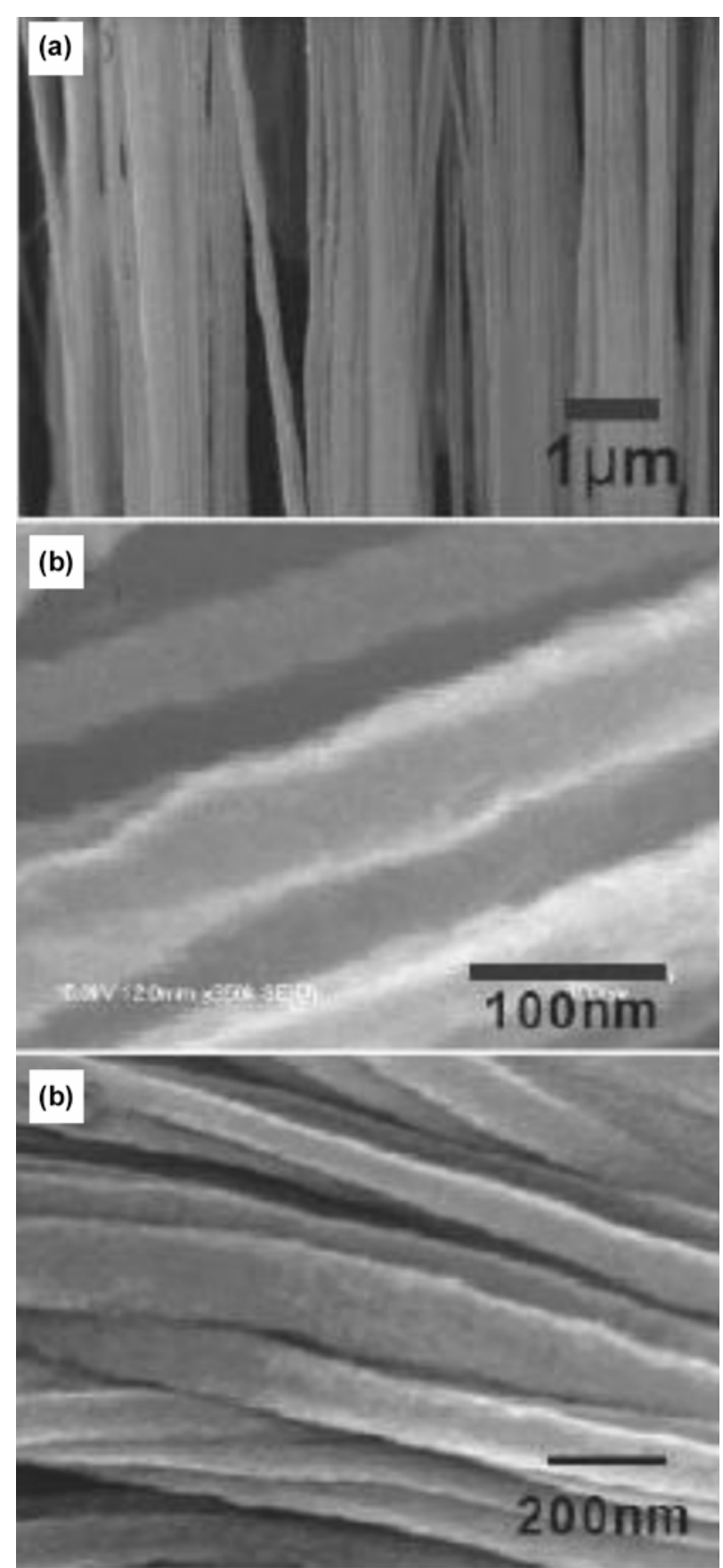

Figure 8. (a) Aligned PAN nanofibres; (b) and (c) SEM images of the $\mathrm{CNF}$ s prepared at $750^{\circ} \mathrm{C}$ at a heating rate of $1{ }^{\circ} \mathrm{C} / \mathrm{min}$.
PAN nanofibres were stabilized at $300^{\circ} \mathrm{C}$ at a heating rate of $1^{\circ} \mathrm{C} / \mathrm{min}$ and then carbonized at $750^{\circ} \mathrm{C}$ with a heating rate of $1{ }^{\circ} \mathrm{C} / \mathrm{min}$.

Figures $8(\mathrm{~b})$ and (c) are the SEM images at different magnifications of the aligned CNFs after carbonization. Majority of the fibres after carbonization were in the diameter range from $60-90 \mathrm{~nm}$ and average diameter was about $80 \mathrm{~nm}$. The production of so thin carbon nanofibres with alignment on large scale was not reported so far apart from the present results.

Figure 9 shows TEM images of the CNFs, where figure 9(c) is the HRTEM image measured at the edge area of the CNF shown in figures 9(a) and (b). It is clearly observed that the structure of the surface layer is different from that of the inner part of the CNF. The inner part is composed of the ordered domains of graphitic layers and the amorphous area. The size of the ordered domain is from several layers to $4.3 \mathrm{~nm}$, which is in agreement with the calculated results from the Raman peaks shown in figure 7(b). However, the surface layer is much better graphitized and preferential orientation of the graphitic layers along the fibre axis is clearly observed in the
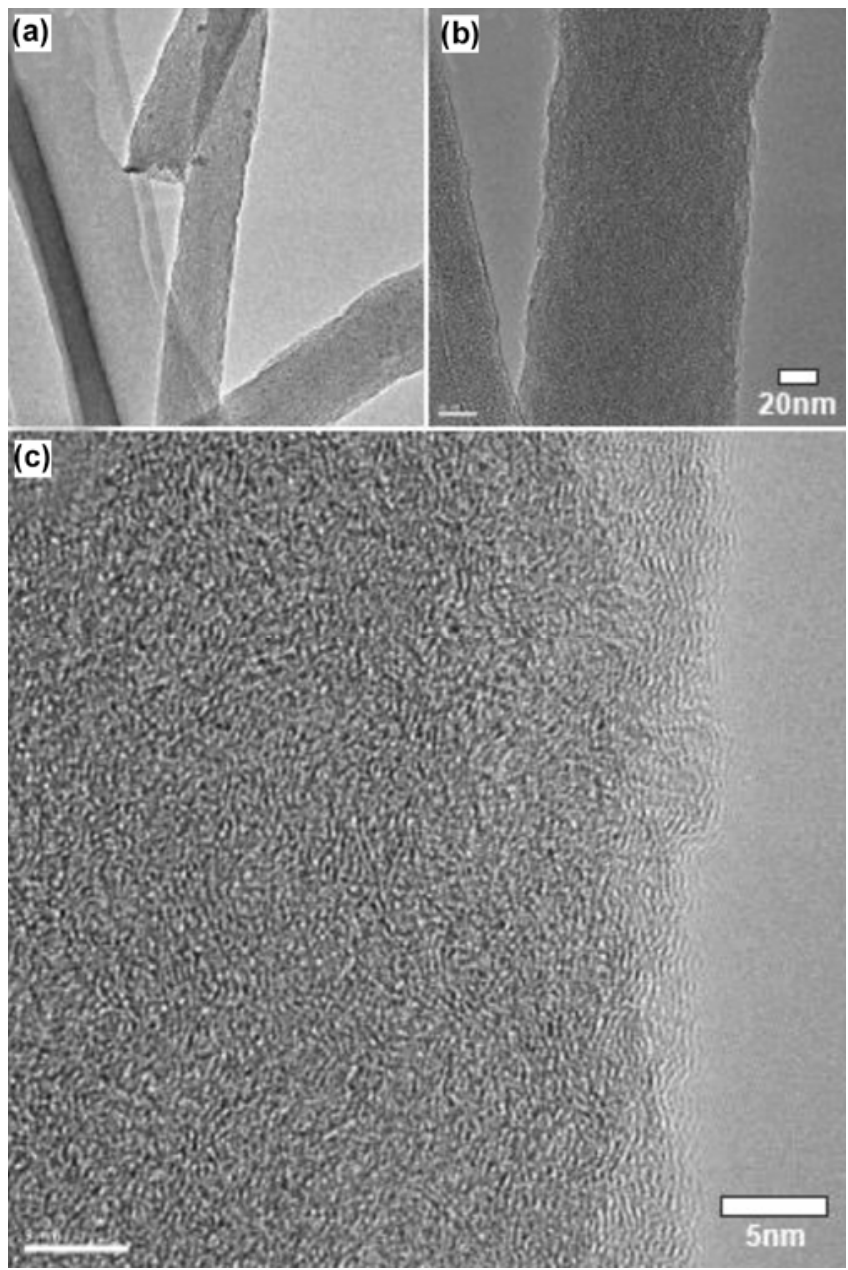

Figure 9. TEM (a), (b) and HRTEM (c) images of the CNFs. 
surface layer. Formation of the oriented atomic layers in the surface part is likely to originate from the preferential orientation of the molecular chains in the precursor PAN fibres. The molecular chains in the surface layer are easier to be aligned during elongation of the electrospinning than those in the inner part. So the surface layer shows much better crystallinity and orientation of the atomic layers than that in the inner part. The thickness of the surface layer is $15-25 \mathrm{~nm}$. In addition, more or less orientation along the fibre axis was also observed for the graphitic layers in the inner part of the CNF, which also resulted from the alignment of the molecular chains in the PAN fibres caused by the large elongating strain during electrospinning. The orientation of the atomic layers along the fibre axis is helpful for improving the mechanical properties of CNFs.

\section{Conclusions}

In conclusion, this paper presents the fabrication route of the ultra thin and aligned CNFs from electrospun PAN nanofibres using a modified electrospinning set up followed by heat treatment. This modified electrospinning set up can readily produce ultra thin precursor nanofibres, which is a prerequisite for obtaining the ultra thin CNFs. The ultra thin and aligned CNFs with an average diameter of about $80 \mathrm{~nm}$ were prepared successfully by this modified set up. DTA/TG analysis and FTIR spectra revealed the chemical reaction occurring during stabilization and carbonization. The stabilization temperature of $300^{\circ} \mathrm{C}$ was determined, whereas lower stabilization temperature of $200^{\circ} \mathrm{C}$ caused the nanofibres to merge together during carbonization. Higher temperature increase up to $5^{\circ} \mathrm{C} / \mathrm{min}$ caused the CNFs to break during carbonization, which can be avoided by decreasing the temperature rate to $1^{\circ} \mathrm{C} / \mathrm{min}$. The CNFs carbonized on substrates are straighter and thinner than that of the free samples, which is because the nanofibres cannot shrink freely on the substrates. Raman spectra and XRD pattern confirmed the carbonization of the PAN nanofibres and it was found that with increasing carbonization temperature the degree of graphitization increases. The crystallite size calculated from the Raman peaks is in the range of $4 \cdot 17-4.62 \mathrm{~nm}$ depending on the carbonization temperature, in agreement with the observation results by HRTEM. The outer part of the CNFs shows much better crystallinity than that in the inner part. The preferential orientation of the atomic layers along the fibre axis was clearly observed for the outer part, which is because the molecular chains in the outer part have higher mobility, and thus aligned much better during elongation process of electrospinning.
The ultra thin and aligned CNFs are especially useful for composite materials.

\section{Acknowledgements}

Financial support from the NSFC (Grant No. 50572019), MOE of China, S\&T Program of Shenzhen government is acknowledged. Cooperation from PAEC and HEC Pakistan is greatly acknowledged.

\section{References}

Babu V S and Seehra M S 1996 Carbon 341259

Chun I S, Reneker D H, Fong H, Fang X, Deitzel J and Tan N B J 1999 Adv. Mater. 3136

Chung G S, Jo S M and Kim B C 2005 J. Appl. Polym. Sci. 97165

Cui H, Kalinin S V, Yang X and Lowndes D H 2004 Nano Lett. 42157

Deitzel J M, Kleinmeyer J, Harris D and Tan N C 2001 Polymer 42261

Endo M, Kim Y A, Ezaka M, Osada K, Yanagisawa T, Hayashi

T, Terrones M and Dresselhaus M S 2003 Nano Lett. 3723

Hammel E, Tang X, Trampert M, Schmitt T, Mauthner K, Eder A and Potschke P 2004 Carbon 421153

Huang Z M, Zhang Y Z, Kotaki M and Ramakrishna S 2003 Comp. Sci. \& Technol. 632223

Kim C and Yang K S 2003 Appl. Phys. Lett. 831216

Kim C, Kim Y J and Kim Y A 2004a Solid State Commun. 132567

Kim C, Park S H, Lee W J and Yang K S 2004b Electrochim Acta $\mathbf{5 0} 877$

Kim C et al 2007 Solid State Commun. 14220

Knight D S and White W B 1989 J. Mater. Res. 4385

Li D, Wang Y L and Xia Y N 2003 Nano Lett. 31167

Li H J, Li J J and Gu C Z 2005 Carbon 43849

Rafique J, Yu J, Yu J L, Fang G, Wong K W, Zheng Z, Ong C H and Lau W M 2007 Appl. Phys. Lett. 91063126

Reneker D H and Chun I 1996 Nanotechnology 7216

Reneker D H, Yarin A L, Fong H and Koombhongse S $2000 \mathrm{~J}$. Appl. Phys. 874531

Rutledge S L, Shaw H C, Benavides J B, Yowell L L, Chen Q, Jacobs B W, Song S P and Ayres V M 2006 Diamond Relat. Mater. 151070

Singh C, Quested T, Boothroyd C B, Thomas P, Kinloch I A, Abou-Kandil A I and Windle A H 2002 J. Phys. Chem. B106 10915

Sutasinpromprae J, Jitjaicham S, Nithitanakul M, Meechaisue C and Supaphol P 2006 Polym. Int. 55825

Yang K S, Edie D D, Lim D Y, Kim Y M and Choi Y O 2003 Carbon 412039

Yokoyama A et al 2005 Nano Lett. 5157

Zhu H W, Li X S, Ci L J, Xu C L, Wu D H and Mao Z Q 2003 Mater. Chem. Phys. 78670

Zussman E, Chen X, Ding W, Calabri L, Dikin D A, Quintana J P and Ruoff R S 2005 Carbon 432175 